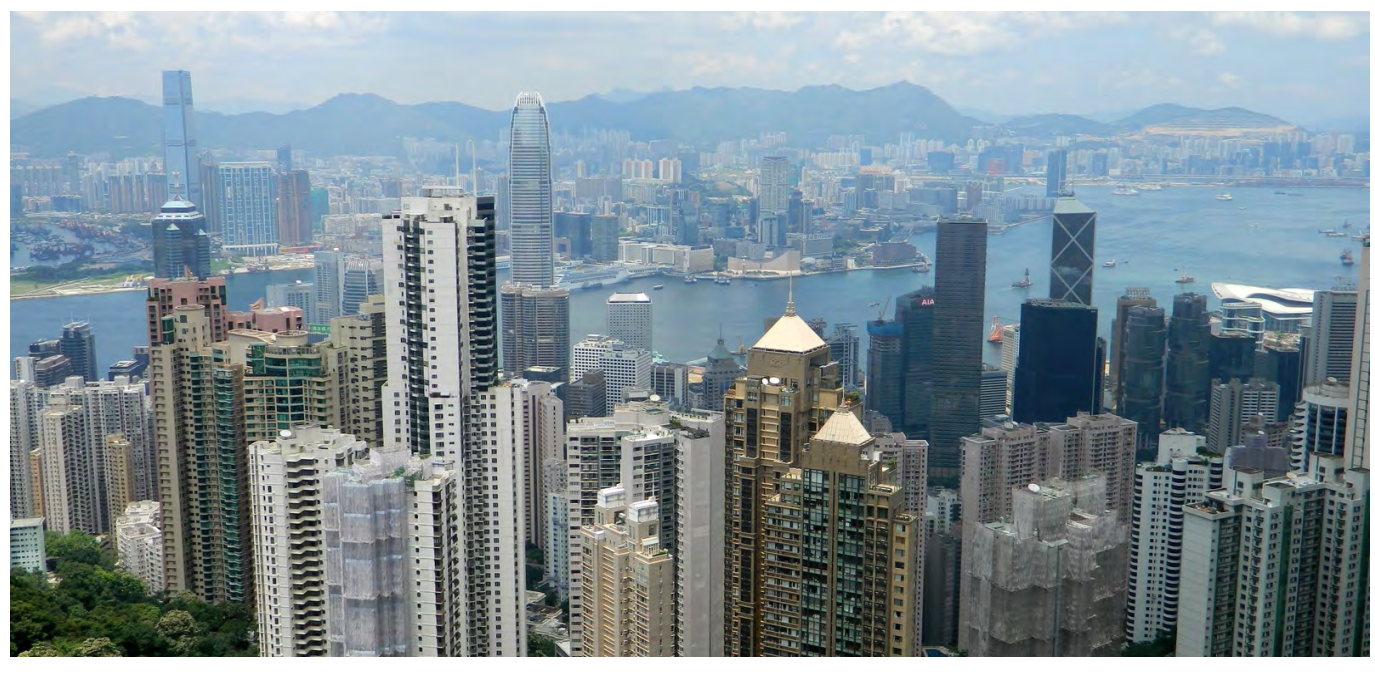

Hong Kong, Victoria Peak. PC: (CC) Allan Watt.

\section{Why Is \\ Reconciliation \\ Impossible? \\ On the Clash of Emotions \\ between Hong Kong and \\ Mainland China}

\section{Shih-Diing LIU \\ Wei SHI}

This essay presents an affective analysis of the antagonism between Hong Kong and mainland China. It illustrates the contexts in which the conflicts are driven by an accumulation of emotional experiences and imaginaries. The divergent emotional positions should be understood as a consequence of nationalism and nativism. Fear and pride are two opposing emotional structures that have become the material basis of ongoing confrontations. Each side uses its own experience to erase that of the other, making regional reconciliation difficult. We suggest that comparing the two structures of feeling helps identify the psychological mechanisms at work.

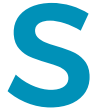
ince the 1997 handover, tensions between Hong Kong and mainland China have been running high. The strained relationship is driven not only by the deep-seated contradictions embedded in the 'One Country, Two Systems' arrangement, but also by a historical accumulation of mutual emotions, experiences, and imaginaries. Feelings such as anxiety, frustration, and fear have become the most obvious components of the crisis, producing a range of political practices and effects on Hong Kong's postcolonial landscape.

Our thinking about the Hong Kong question is propelled by our reflections on the role of identity and emotional memories in sustaining the hostilities between mainland China and its margins 
(Shi 2007; Liu 2005, 2008, 2018). In recent years, the intensified conflicts between Hong Kong and mainland China have triggered our interest in understanding the historical factors that produce different emotional experiences.

Although the conflicts between Hong Kong and mainland China are driven by multiple factors, we believe that differences in identity and self-understanding play a crucial role. We argue that Hong Kong's fear and China's pride constitute two distinctive and clashing emotional structures that have become the affective material basis of ongoing confrontations. In what follows, we contextualise the emotional forces that have gathered to intensify such conflicts.

\section{From Localism to Nostalgia}

In Hong Kong, the experiences of British colonial rule and the Cold War cultivated a sense of localism (Law 2007). In the 1980s, negotiations between the Chinese and British governments prompted Hong Kong's citizens to reflect on their identity and culture. During this time, Hong Kong gradually developed a sense of self and collective emotions, including feelings of superiority compared with the economically disadvantaged mainland (Law 2009). At roughly the same time, local academics and artists began exploring the cultural and historical roots of Hong Kong, emphasising the uniqueness of the city's lifestyle and cultural milieu, as well as the complex nature of the historical colonial experience (Abbas 1997; Law 2009; Chun 2017).

In the 1990s, some scholars described Hong Kong as struggling to survive between its two colonisers (Chow 1995: 94); 'localism' was regarded as a form of rebellion against colonial rule. During the late colonial era, a discourse emphasising the uniqueness and autonomy of Hong Kong's culture was inevitably entangled with the binary political imagination formulated during the Cold War, which was framed as the dichotomy of 'totalitarian China versus democratic Hong Kong'. As mainland scholar Qiang Shigong (2008: 90) observed, when faced with Western notions of human rights, rule of law, democracy, and universal suffrage, China is 'in a state of aphasia' and unable to offer competing discourses. This has made it immensely difficult to win the hearts and minds of Hong Kong's people.

However, local resistance to 'renationalisation' (Erni 2001) and the democracy movement against the Chinese state have combined to reinforce nostalgia for colonialism and the persistent obsession with the uniqueness of the local culture. Some scholars have therefore noted the risk of Hongkongers becoming fixated on localism (Lo and Pang 2007), the 'Great Hong Kong Chauvinism' as well as the essentialised 'Us versus Them' structure (Hung 1997; Ip 1997). As a result, the colonial mindset that saw China as underdeveloped, barbaric, and backward has been preserved. As Chow Wing Sun (2015: 103) observed:

\section{The thought of 'Great Hong Kong' has been deep-rooted into the minds of the Hong Kong people, who believe that everything about Hong Kong is superior to mainland China, so that they look down on mainland Chinese, and disdain their own Chinese iden- tity.}

This is the reason cultural critic Chan Koon-Chung (2012) urged the need to reflect on the tendency to essentialise discourses of Hong Kong localism.

\section{Intensification of Fear}

In this sense, intensification of the conflict between Hong Kong and mainland China in recent years should be understood not simply in politico-economic terms, but as a result of the emotional and psychological state driven by nationalism and nativism (Chen 2010: 156-57). Hong Kong's collective sense of uncertainty, insecurity, anxiety, depression, and fear about the futurewhich are frequently mixed with distrust, frustration, and anger-can be traced back to the signing of the Sino-British Joint Declaration in 1984 that determined the fate of Hong Kong after 1997. Since then, such emotions have never faded, but have been expressed in Hong Kong's popular culture 


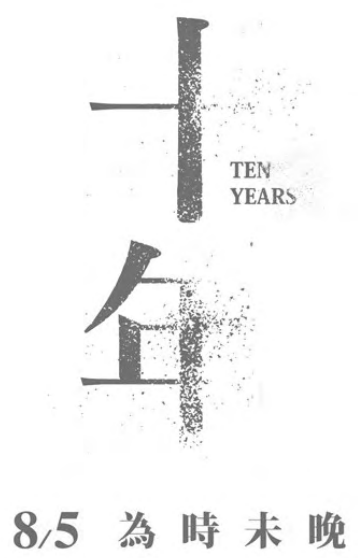

and continue to shape Hong Kong's subjectivities. Chow Wing Sun (2015: 126) described the collective feelings of the Hong Kong people in the following terms:

\section{After its return to China, Hong Kong people feel fearful towards their home country, as they are afraid that the Chinese government would impose the governance approach for the mainland Chinese on them. Moreover, due to the different systems, things that happened in mainland China might appear to be ridiculous and unacceptable to Hong Kong people.}

Hong Kong's collective sentiment towards mainland China is obviously complicated. This can be seen clearly in contemporary Hong Kong cinema, which has been obsessed with the 'othering' of China as a means of constituting Hong Kong subjectivity. Some Hong Kong movies explicitly feature the destructiveness of a pervasive, powerful, violent, and fearful 'China', which is characterised as making the lives of Hong Kong people difficult and miserable, and which imagines China as the
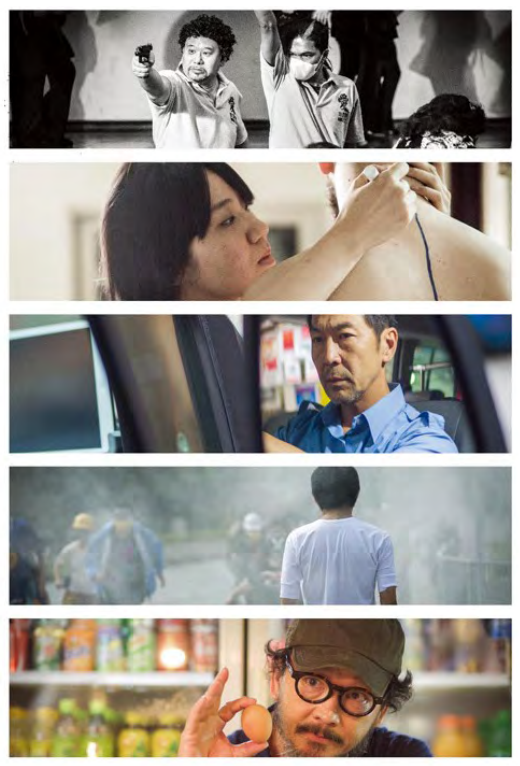

Ten Years (十年, 2015).

source of uneasiness and fear. Others portray China as an old-fashioned, backward, yet intimate and ambivalent Other with which to live beside (Shi 2019). In the wake of the Tiananmen incident in 1989, the fear of a despotic, tyrannical China triggered more negative feelings in Hong Kong such as hopelessness and despair. Since the handover, there has been a growing tendency to highlight a sense of powerlessness and anger due to the perception that people in Hong Kong cannot freely decide their own future and way of life-a trend that culminated in 2015 with the release of the movie Ten Years (十年).

Released in the wake of the Umbrella Movement and against the backdrop of Chinese President Xi Jinping's call for China's national rejuvenation, the film can be seen as a turning point in the intensification of Hong Kong's politics of fear of the Chinese Other. The movie highlights the pain China brought to Hong Kong and its people, with their fate portrayed as tragic and miserable, entirely deprived of dignity. It features the 'invasion' of tourists from the mainland, the invisible power threatening Hong Kong's political autonomy, the disappearance of local cultures, as well as 




Amazing China (厉害了, 我 的国, 2018)

the brainwashing of local youngsters. 'China' is portrayed as an aggressive, insidious, malicious, and unscrupulous oppressor depriving Hongkongers of their rights and freedom. Such a fearsome image is in stark contrast with the discourse of the 'Chinese Dream' and its underlying triumphalism, which is promoted by popular culture and in the media on the mainland.

Ten Years offers an emotional narrative through which to articulate and reinforce the politics of fear that motivates Hong Kong's resistance to state power, which has two features. First, Hong Kong is constructed as the injured and victimised subject under threat and unable to maintain its way of life or dignity, whose people are ultimately unable to control their own destiny. Second, articulated through hatred for the enemy, this politics of fear leads to the cultivation of a rebellious subject who is self-determined and uncompromising when fighting the enemy. The self-other relationship is defined in absolute moral and antagonistic terms of binary opposition that make reconciliation impossible. Imbued with intense feelings of dissatisfaction, indignation, and disgust, the politics of fear calls for an active and radical political practice to change Hong Kong's fate in more direct and confrontational ways.

\section{Emergence of a Proud Subject}

The shift in Hong Kong's collective emotions should be understood with reference to the concurrent triumphalist mood on the mainland, where nationalism has intensified since the late 1990s (Qian 2016). The complex experiences of China's modernisation have created fertile ground for nationalism. The formation of the modern Chinese nation-state overlapped with its experience of humiliation at the hands of foreign powers so that the way Chinese imagine their 'Century of Humiliation' has a powerful influence on the disposition towards nationalism today-manifested, in particular, in the persistent drive to rebuild a strong nation (Chen 2010; Gries 2004). 
Since 1949, the political constitution of the national subject in mainland China has been transfixed by a reservoir of stories about the country's shameful past. Shame has been a key component of China's nation-building process. The psychological effects of the traumatic encounters with Western aggression include feelings of anxiety, fear, resentment, humiliation, and grief, accompanied by self-defensiveness and a longing for restoration. Such a mental state has shaped a world view that is grounded in the idea of 'the survival of the fittest', which in turn has fostered the desire for China to become a superpower that can compete with the West, which has driven much of China's nationalism and modernisation.

Our previous analysis of the cinematic production of national pride in the era of Xi Jinping illustrates the most recent psychic transformation of Chinese nationalism (Shi and Liu 2020). Since Xi came to power, his regime has engineered a new nationalist subject in the Chinese Dream through state-sanctioned media narratives. The TV documentary Amazing China (厉害了, 我的国, 2018), co-produced by the state-owned China Central Television and China Film, demonstrates that the formation of the new national subject is articulated by advanced technology and invested with a strong sense of self-confidence. The continuing obsession with national strength and great power is manifested in TV productions such as The Rise of the Great Powers (大国崛起, 2006) and The Road to Rejuvenation (复兴之路, 2007). With China now the world's second-largest economy and a regional superpower, the reinvention of pride as nationalism has gained social currency and produced various imaginaries of China's superior position in the world.

Underlying the nation's growing assertiveness is a profound desire to rewrite a history marked by pain and suffering. It is driven by the desire to demonstrate the overcoming of the shame of the past, and the restoration of the dignity of the formerly insulted, humiliated, and outraged subject. The new sense of pride is generated by a psychic reinvention of historical memories and experiences in the new geopolitical context of great power politics. Simply put, a double articulation of China's historical legacies is at work: the new, desiring subject inherits the political ambition of the Maoist period and rearticulates a desire to be modernised in the reform era. As illustrated in the 2017 film Wolf Warrior 2 (战狼 2)-in which a Chinese special forces operative travels to Africa to deal with a sadistic band of mercenaries terrorising innocent civilians-the subject of the Chinese Dream desires to be technologically advanced and intends to take the place of the Western Other.

\section{Us Versus Them as Political Manifestation}

Hong Kong's fear and China's pride constitute two opposing emotional structures that have become the material basis of ongoing conflicts. In the binary relationship between Hong Kong and mainland China, British colonial modernity is always an 'absent presence' in Hong Kong's self-imagination. This internalised Other is invested with a variety of cultural imaginaries such as modernity and civilisation that cultivate a sense of superiority. In this sense, Hong Kong's anti-China complex and pro-West subjectivities are inseparable. Its emotional energy is exemplified in a series of localist movements.

However, Hong Kong is never a purely foreign Other in the perception of mainland China. Rather, Hong Kong is a compatriot once ruled by the West-a victim of colonial humiliation. Its existence is evidence of the arrogance and greed of colonialism. The nationalist narrative frames the 1997 handover in terms of the Chinese people's history of suffering and a common ancestry, erasing Hong Kong's own emotional experiences.

With the increasing regional integration of the enclave into the Guangdong-Hong Kong-Macau Greater Bay Area, the former British colony no longer enjoys a unique status. Meanwhile, mainland China is no longer lagging Hong Kong in terms of modernisation and economic power. The changes between the two further solidify their emotional positions. Fear represents Hong Kong's uneasiness and anxiety about these changes, while pride signifies China's emotional transformation 
from a weak to a powerful position. Each side uses its own experience to ignore that of the other-an approach that has made regional reconciliation more difficult.

The tensions between mainland China and Hong Kong provide an opportunity to understand the psychological impact of the rise of China. Whether it is fear or pride, we believe these collective feelings are essential elements to understand the conflict. The affective disjuncture can be seen as a consequence of different aspirations for and pursuits of modernity. Due to the different psychological forces at work, each entity has developed different emotionally charged imaginaries of the self and the other. The self-centrism and enclosure of each's imagination cannot cope with the complicated and changing present. We agree with Baik Youngseo's (2016) claim that the key to reconciliation is the subjects' ability to 'share each other's agony and sufferings' and to feel for and understand one another. He Zhaotian (2005: 255) believes the key to reconciliation in Asia lies in the 'awareness, sympathy, entry, understanding and sharing of the other's deep-seated confusion and worries'. When both parties imagine and construct relations with the other in an opposing manner, only resentment, hostility, and hatred are cultivated. Juxtaposing the two affective planes helps identify the internal mechanisms at work.

The question is: What dialogic space could be opened with this kind of emotional divergence? How can the emotions of both sides be mutually recognised? How can both sides avoid the dangers of parochial identity politics and narcissistic self-centrism? These questions demand a new mode of inquiry and intellectual practice to overcome the platitudes of the political domain. The ongoing tensions may offer a starting point for attending to the emotional dimensions that are central to the future of China. 
This text is taken from Made in China Journal: Volume 6, Issue 3, 2021, edited by Ivan Franceschini, Nicholas Loubere and Shui-yin Sharon Yam, published 2022 by ANU Press, The Australian National University, Canberra, Australia.

doi.org/10.22459/MIC.06.03.2021.15 